\title{
Precipitated Phases and Corrosion Behavior in the Dissimilar Alloy 690-SUS 304L Joints Formed by EBW and GTAW
}

\author{
Hwa-Teng Lee ${ }^{1, *}$, Yong-Ding Lin ${ }^{1}$, Tsung-Yuan $\mathrm{Kuo}^{2}$ and Sheng-Long Jeng ${ }^{3}$ \\ ${ }^{1}$ Department of Mechanical Engineering, National Cheng Kung University, Tainan 701, Taiwan, R. O. China \\ ${ }^{2}$ Department of Mechanical Engineering, Southern Taiwan University of Technology, Tainan 710, Taiwan, R. O. China \\ ${ }^{3}$ Nuclear Fuel and Materials Division, Institute of Nuclear Energy Research, Lungtan 1000, Taiwan, R. O. China
}

This study investigates the correlation between the microstructure and the corrosion resistance properties of the fusion zone of Alloy 690SUS 304L stainless steel dissimilar weldments formed by electron beam welding (EBW). The effects of the EBW process are evaluated by comparing the microstructure and corrosion resistance properties of the EBW weldment with those of Alloy 690-SUS 304L weldment formed by gas tungsten arc welding (GTAW). The experimental results reveal that the interdendritic region of the fusion zone of the EBW weldment contains fine TiN precipitates and $\mathrm{Cr}-\mathrm{Ni}$ rich phases. The TiN precipitates are originated from the Alloy 690 base metal, while the $\mathrm{Cr}-\mathrm{Ni}$ rich phases, a new formation of precipitates, is precipitated in the region around TiN during solidification. Microscopic analysis of the samples following a modified Huey test indicates that the matrix around TiN precipitate and the $\mathrm{Cr}$-Ni rich phase precipitate provide the preferred sites for corrosion pit initiation. Due to the rapid cooling in the EBW process, relatively fewer and smaller TiN precipitates and $\mathrm{Cr}$-Ni rich phases are formed in the weldment. Consequently, only limited corrosive pitting is observed which indicates better interdendritic corrosion resistance properties in comparison to joints with GTAW process. Furthermore, rapid solidification in the fusion zone results not only the suppression of chromium carbide precipitation but also the chromium depletion at the grain boundaries. As a result, the intergranular corrosion resistance and interdendritic corrosion resistance of the EBW weldment are significantly higher than that of the GTAW weldment. [doi:10.2320/matertrans.MER2007010]

(Received January 12, 2007; Accepted March 27, 2007; Published May 25, 2007)

Keywords: electron beam welding, precipitates, interdendritic corrosion, intergranular corrosion, dissimilar welding

\section{Introduction}

Early maintenance records from nuclear power plants reported the occurrence of cracks in components formed by the dissimilar welding of Alloy 600 and SUS 308 stainless steel (SS). Investigations revealed that these cracks were primarily the result of a poor corrosion resistance of the weldment and an improper slot in the weldments. ${ }^{1)}$ In an attempt to improve the corrosion resistance of these dissimilar weldments, this study replaces the Alloy 600 and SUS 308 SS with higher chromium contained Alloy 690 and lower carbon contained SUS 304L SS, respectively.

The chromium content of Alloy 690 (29 mass-\%Cr-59 mass- $\% \mathrm{Ni}-10$ mass- $\% \mathrm{Fe}-0.02$ mass- $\% \mathrm{C}$ ) is almost twice that of Alloy 600 (16 mass- $\%$ Cr-75 mass- $\%$ Ni- 8 mass- $\%$ Fe- 0.023 mass- $\% \mathrm{C})^{2,3)}$ which substantially reduced the tendency of chromium depletion caused by carbide segregation at the grain boundaries and enhanced the corrosion resistance. ${ }^{4)}$ Previous studies ${ }^{5-7)}$ have also indicated that the stress corrosion cracking resistance, intergraular corrosion resistance and the surface corrosion resistance of Alloy 690 are better than that of Alloy 600. Alloy 690 has been widely applied to repair the degraded Alloy 600 components of nuclear power plants. Meanwhile, SUS 304L SS (18 mass-\%Cr-8 mass$\% \mathrm{Ni}-72$ mass- $\% \mathrm{Fe}-0.013$ mass-\%C) with extra low carbon content is employed here to replace SUS 308 SS (19 mass$\% \mathrm{Cr}-10$ mass- $\% \mathrm{Ni}-70$ mass- $\% \mathrm{Fe}-0.08$ mass-\%C). Lower carbon content reduces the precipitation of carbide in the fusion zone. Such substitution, Alloy 690-SUS 304L is practically superior to the common Alloy 600-SUS 308 concerning to the corrosion resistance.

*Corresponding author, E-mail: htlee@mail.ncku.edu.tw
Furthermore, traditional welding processes such as shielded metal arc welding, gas metal arc welding, or gas tungsten arc welding (GTAW) are used as common welding process in nuclear power plants for components joining. Lee et al. ${ }^{8-11)}$ showed that the fusion zones of the weldments formed using these methods had a highly brittle eutectic structure with a low melting point and a low strength. As a result, the fusion zone is prone to hot cracking during solidification. It has been reported that the addition of suitable quantities of niobium and titanium to the filler metal refines the grain size, and hence improves the mechanical strength of the weldment. ${ }^{12-15)}$ However, due to the Nb-rich and Ti-rich eutectic-like structure of the fusion zone and the precipitation of chromium carbide at the grain boundaries, the welding process and method mentioned above are not able to prevent hot cracking completely or improve corrosion resistance effectively. In addition, many of the components used in nuclear power plants are fabricated from thick plates, the number of welding passes required to accomplish the joint is often very high. As a result, the weldments are subject to a greater thermal cycling effect, a higher total heat input, and a more extensive heat-affected zone (HAZ). It has been widely reported that these characteristics degrade both the mechanical properties and the corrosion resistance of the weldment. ${ }^{12,13)}$

In contrast to the conventional welding processes discussed above, electron beam welding (EBW) is a high energy density beam welding technique, and is therefore capable of welding thick components in a single pass for use in nuclear power plants. EBW has many advantages, including a low total heat input, a high depth-to-width ratio, low distortion, a high welding speed. They all help to reduce the welding stress and suppresses stress corrosion cracking. Therefore, 
Table 1 Compositions of Alloy 690 and SUS 304L stainless steel base metals (mass-\%).

\begin{tabular}{cccccccccccccccccccccc}
\hline Base Metal & $\mathrm{Cr}$ & $\mathrm{Ni}$ & $\mathrm{Fe}$ & $\mathrm{C}$ & $\mathrm{Si}$ & $\mathrm{Mn}$ & $\mathrm{P}$ & $\mathrm{S}$ & $\mathrm{Ti}$ & $\mathrm{Cu}$ & $\mathrm{Al}$ & $\mathrm{Co}$ & $\mathrm{Mo}$ & $\mathrm{V}$ \\
\hline Alloy 690 & 28.73 & Bal. & 10.01 & 0.02 & 0.26 & 0.31 & 0.01 & 0.001 & 0.30 & 0.02 & 0.12 & 0.014 & - & - \\
SUS 304L & 17.88 & 8.22 & Bal. & 0.013 & 0.61 & 1.62 & 0.024 & 0.003 & - & 0.08 & - & - & 0.06 & 0.09 \\
\hline
\end{tabular}

Table 2 Welding parameters used in EBW process.

\begin{tabular}{|c|c|c|c|c|c|}
\hline Vacuum $(\mathrm{Pa})$ & Voltage $(\mathrm{kV})$ & Current (mA) & Power (W) & Welding Speed $\left(\mathrm{mm} \cdot \mathrm{s}^{-1}\right)$ & Heat Input $\left(\mathrm{kJ} \cdot \mathrm{mm}^{-1}\right)$ \\
\hline $8 \times 10^{-3}$ & 50 & 26 & 1300 & 50 & $2.6 \times 10^{-2}$ \\
\hline
\end{tabular}

Table 3 Composition of Inconel filler metal 52 (I-52) (mass-\%).

\begin{tabular}{cccccccccccccccc}
\hline Material & $\mathrm{Ni}$ & $\mathrm{Cr}$ & $\mathrm{Fe}$ & $\mathrm{Mn}$ & $\mathrm{Ti}$ & $\mathrm{C}$ & $\mathrm{Si}$ & $\mathrm{Cu}$ & $\mathrm{Al}$ & $\mathrm{P}$ & & $\mathrm{S}$ & & & \\
\hline $\mathrm{I}-52$ & 60.65 & 28.83 & 8.86 & 0.24 & 0.51 & 0.03 & 0.15 & 0.01 & 0.71 & 0.003 & 0.001 & \\
\hline
\end{tabular}

Table 4 Procedures and parameters used in GTAW process.

\begin{tabular}{|c|c|c|c|c|c|c|}
\hline \multirow[b]{2}{*}{ Pass Sequence } & \multirow[b]{2}{*}{ Pass No. } & \multicolumn{4}{|c|}{ Welding Parameters } & \multirow{2}{*}{$\begin{array}{c}\text { Total } \\
\text { Heat Input } \\
\left(\mathrm{kJ} \cdot \mathrm{mm}^{-1}\right)\end{array}$} \\
\hline & & $\begin{array}{l}\text { Current } \\
\text { (A) }\end{array}$ & $\begin{array}{c}\text { Voltage } \\
\text { (V) }\end{array}$ & $\begin{array}{c}\text { Speed } \\
\left(\mathrm{mm} \cdot \mathrm{s}^{-1}\right)\end{array}$ & $\begin{array}{l}\text { Heat input } \\
\left(\mathrm{kJ} \cdot \mathrm{mm}^{-1}\right)\end{array}$ & \\
\hline & 1 & 120 & 12 & 1.47 & 1.640 & \multirow{6}{*}{7.830} \\
\hline & 2 & 120 & 12 & 1.58 & 1.520 & \\
\hline & 3 & 120 & 12 & 2.42 & 0.990 & \\
\hline 2 & 4 & 120 & 12 & 2.42 & 0.990 & \\
\hline & 5 & 120 & 12 & 1.92 & 1.250 & \\
\hline & 6 & 120 & 12 & 1.67 & 1.440 & \\
\hline
\end{tabular}

$*$ Heat input $=($ Voltage $\times$ Current $) /$ Welding speed

EBW not only has a high welding efficiency, resulting in a shorter welding time, but also enhances the reliability and safety of the welded components of nuclear power plants. It has been widely applied to thick components of nuclear power plants. Consequently, an increasing use in the fabrication of components designed for use in nuclear power plants is high lighted. ${ }^{16-18)}$

In this study, EBW is used to fabricate dissimilar butt weldments of Alloy 690 to SUS 304L SS. The microstructure of the fusion zone is investigated and the elemental distribution in precipitates is studied. The corrosion resistance of the weldments is then analyzed by performing a modified Huey test. Correlations among the microstructure of the fusion zone, the distribution of the alloy elements and the corrosion resistance of the weldments are analyzed. Finally, difference between the EBW and GTAW weldment are compared and evaluated.

\section{Materials and Experimental Procedure}

The Alloy 690 used in this study was purchased in plate form from Sumitomo Metal Technology, Japan. Prior to delivery, the material was solution heat treated at $1050^{\circ} \mathrm{C}$ for 5 minutes and then quenched in water. Meanwhile, the asreceived SUS 304L SS was heat treated in vacuum conditions at $1050^{\circ} \mathrm{C}$ for 80 minutes and was then allowed to cool in nitrogen gas. The elemental compositions of the two base metals are summarized in Table 1. The two base metals were machined into plate specimens measuring $100 \times 70 \times 3 \mathrm{~mm}$. Dissimilar weldments of Alloy 690 and SUS 304L SS were then fabricated using the EBW process. The welding operation of the EBW process was performed in a vacuum atmosphere using the parameters indicated in Table 2 and was conducted without using filler metals. To evaluate the effects of the EBW process on the corrosion resistance of the fusion zone, dissimilar weldments of Alloy 690 and SUS 304L SS were fabricated using the conventional GTAW process with Inconel filler metal 52 (I-52). Pure argon gas (99.9\%) was conducted for shielding. The composition of I52 and the process parameters applied during the GTAW welding process are shown in Tables 3 and 4, respectively."

Microstructural analysis samples were prepared using a mechanical polishing process followed by electrolytic etching at $6 \mathrm{~V}$ DC for $12-20$ seconds in a reagent of $70 \mathrm{ml}$ $\mathrm{H}_{3} \mathrm{PO}_{4}+30 \mathrm{ml} \mathrm{H} \mathrm{H}_{2} \mathrm{O}$. The microstructural observations and compositional analysis were performed using a FieldEmission Scanning Electron Microscope (Philips XL40FEG SEM) equipped with an Energy Dispersive X-ray Spectrometer (EDS).

Foils were thinned by dipping them in an electrolytic solution of $10 \% \mathrm{HClO}_{4}$ and $90 \%$ alcohol $\left(\mathrm{C}_{2} \mathrm{H}_{5} \mathrm{OH}\right)$ at a temperature of $-10^{\circ} \mathrm{C}$. Microstructural analyses of the precipitates in the fusion zone were performed using carbon extraction replicas made using an extraction replication technique. ${ }^{19)}$ The microstructural analysis was performed using a Transmission Electron Microscopy (Philips Tecnai 


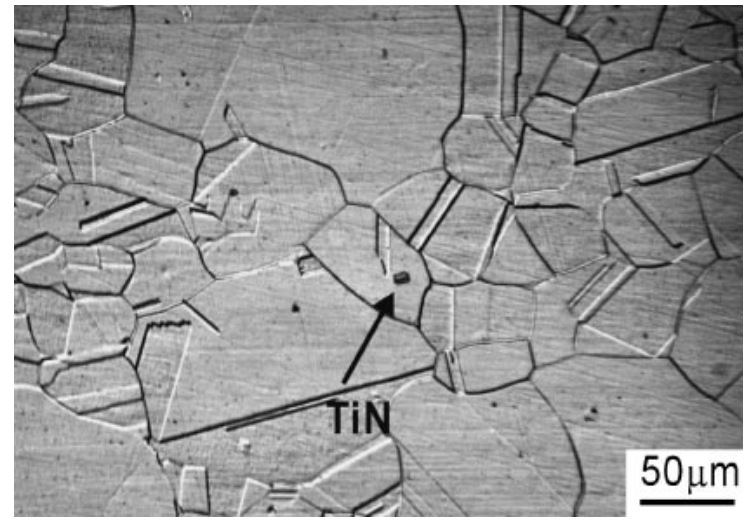

Fig. 1 Optical microstructure of as-received Alloy 690 base metal (heat treated at $1050^{\circ} \mathrm{C}$ for 5 minutes and then water quenched).

F20 STEM) at $200 \mathrm{kV}$, and included Electron Energy Lost Spectrometer (EELS), Selected Area Diffraction Pattern (SADP) and EDS analyses.

The corrosion resistance of the weldments was evaluated using a modified Huey test, in which samples extracted from the weldments were mechanically polished and then etched in a solution of $65 \%$ nitric acid $\left(\mathrm{HNO}_{3}\right)+0.1 \%$ hydrofluoric acid (HF) at a temperature of $117^{\circ} \mathrm{C}$ for four hours. The etched sample surfaces were then examined using a SEM to investigate the corrosion resistance properties.

\section{Results and Discussion}

\subsection{Microstructure of base metal}

Figure 1 shows the optical microstructure of the asreceived Alloy 690 base metal. The microstructure consists primarily of single austenitic phase, but also includes some annealing twins formed during heat treatment and a small amount of rectangular-like TiN precipitates. Figure 2 presents a microstructural and compositional analysis of grain boundary in the Alloy 690 base metal. Figure 2(a) shows the presence of discontinuous oval-like chromium carbide precipitates at the grain boundary. The TEM SADP and EELS analysis results presented in Figs. 2(a) and 2(c) respectively, show these precipitates to be $\mathrm{Cr}_{23} \mathrm{C}_{6}$. The diffraction pattern is well indexed as the precipitates with a lattice parameter of $1.06 \mathrm{~nm}$. The EDS compositional analysis presented in Fig. 2(d) show that the $\mathrm{Cr}_{23} \mathrm{C}_{6}$ precipitates have relatively high chromium content, but are low in nickel and iron. Kai et al. have the same finding presented in the literature. ${ }^{20-22)}$ Figure 2(b) shows that the chromium content at the grain boundary is still maintained at around 29 mass- $\%$. No evident chromium-depleted zone is found around the grain boundary. Figure 3 shows the optical microstructure of the SUS 304L SS base metal. As shown in the figure, the microstructure is characterized by an austenitic phase with delta-ferrite ( $\delta$-ferrite) particles aligned in parallel chain-like structures.

\subsection{Precipitates in HAZ}

Figure 4 presents SEM micrographs of the microstructure and precipitates in the HAZ of the EBW weldment and in the Alloy 690 base metal as well. Precipitates with different size are formed according to their on site locations. Comparing Figs. 4(a) and 4(b), for instance, the chromium carbide precipitates at the grain boundary in the HAZ are smaller than those in the base metal. Further investigation reveal that precipitates in HAZ but closer to the fusion zone are smaller than those away from fusion zone since they are undergone a higher temperature during the welding process. On site of near fusion zone in HAZ, carbide precipitates in grain boundary are disappeared as shown in Fig. 4(c). The disappearance of these precipitates could be accounted by
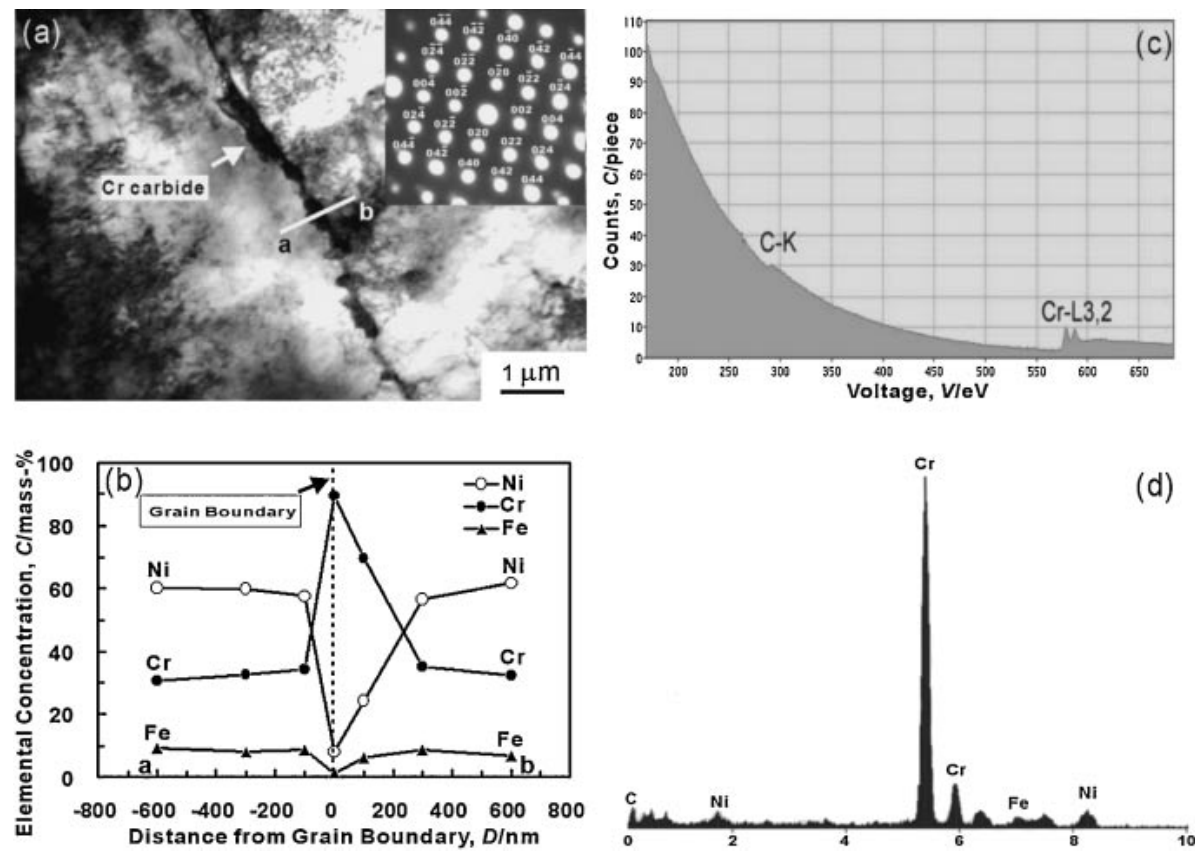

Fig. 2 Microstructure and compositional analysis of grain boundary in Alloy 690 base metal (TEM thin foil specimen): (a) micrograph and [100] SADP showing discontinuous $\mathrm{Cr}_{23} \mathrm{C}_{6}$ precipitates at grain boundary in Alloy 690, (b) variation of $\mathrm{Ni}, \mathrm{Cr}$ and $\mathrm{Fe}$ content across grain boundary, (c) EELS analysis of $\mathrm{Cr}_{23} \mathrm{C}_{6}$, and (d) EDS analysis of $\mathrm{Cr}_{23} \mathrm{C}_{6}$. 


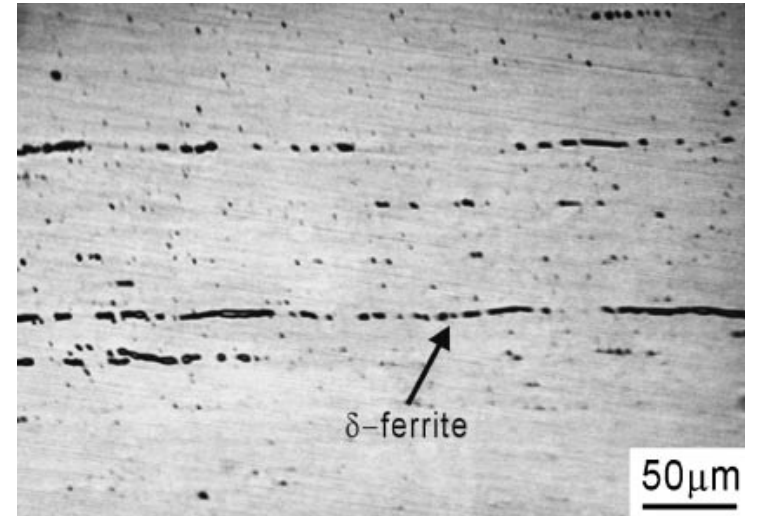

Fig. 3 Optical microstructure of SUS $304 \mathrm{~L} \mathrm{SS}$ treated at $1050^{\circ} \mathrm{C}$ for 80 minutes and then cooled naturally in nitrogen gas.

the following high cooling speed. This is due to carbide precipitates were completely dissolved as a result of the greater welding heat. Besides, since the rapid cooling rate in the EBW process, the precipitates in the fusion zone did not have sufficient time to be precipitate. Figure 4(d) shows the presence of many $\delta$-ferrite in HAZ near the fusion line in the SUS 304L SS. It is a consequence of the lower welding heat and higher cooling rate of the EBW process. David indicated in his publication that insufficient time exists in the EBW process for the $\delta$-ferrite to transform into $\gamma$-austenite, and hence chromium-rich and nickel-depleted $\delta$-ferrite particles remain in the matrix following cooling. ${ }^{23)}$

\subsection{Microstructure in fusion zone}

Figure 5 presents SEM images of the precipitates in fusion zone of the EBW weldment. Two different precipitates can be identified. The EDS analysis results reveal that the precipitates formed near the fusion line in the fusion zone with somewhat rectangular or rounded rectangular shape (see Figs. 5(a) and 5(b)) are TiN. The presence of these precipitates in fusion zone is due in part to the fact that the region remains at a high temperature for only a short time as a result of the high cooling rate in the EBW process. Furthermore, TiN precipitates have a high melting point (i.e. $1950^{\circ} \mathrm{C}$ ). Consequently, these precipitates are either not dissolved at all (as shown in Fig. 5(b)) or are only partially dissolved (as shown in Fig. 5(a)). In addition to TiN, Fig. 5 also shows the formation of $\mathrm{Cr}-\mathrm{Ni}$ rich phase in the form of particle precipitate in the interdendritic region. Comparing the cap and root regions of the weldment, shown in Figs. 5(c) and $5(\mathrm{~d})$, it is seen that both the size and the number of the interdendritic precipitates reduce in the root region. This result is to be expected since the cooling rate is higher in the root region of the weldment. As a result, the time for which the root area remains at a high temperature is shorter and hence the solidification time is reduced.

The TEM micrograph of TiN with rectangular shape is shown in Fig. 6. The TiN in the fusion zone are significantly smaller than those near the fusion line. Figure 6(a) shows the TEM micrograph together with its SADP in [101] zone axis. TEM EELS analysis results presented in Fig. 6(b) reveal that these rectangular precipitates consist primarily of nitrogen, titanium, chromium and carbon. The carbon peak in Figure originates from the carbon film of the carbon extraction replica which should be omitted. The TEM EDS analysis results shown in Fig. 6(c) indicate that the TiN precipitates have a titanium content of around 69.33 mass- $\%$, and chromium, nitrogen and aluminum contents of 12.44 masss$\%, 8.98$ masss- $\%$ and 9.25 masss- $\%$, respectively. It is clear

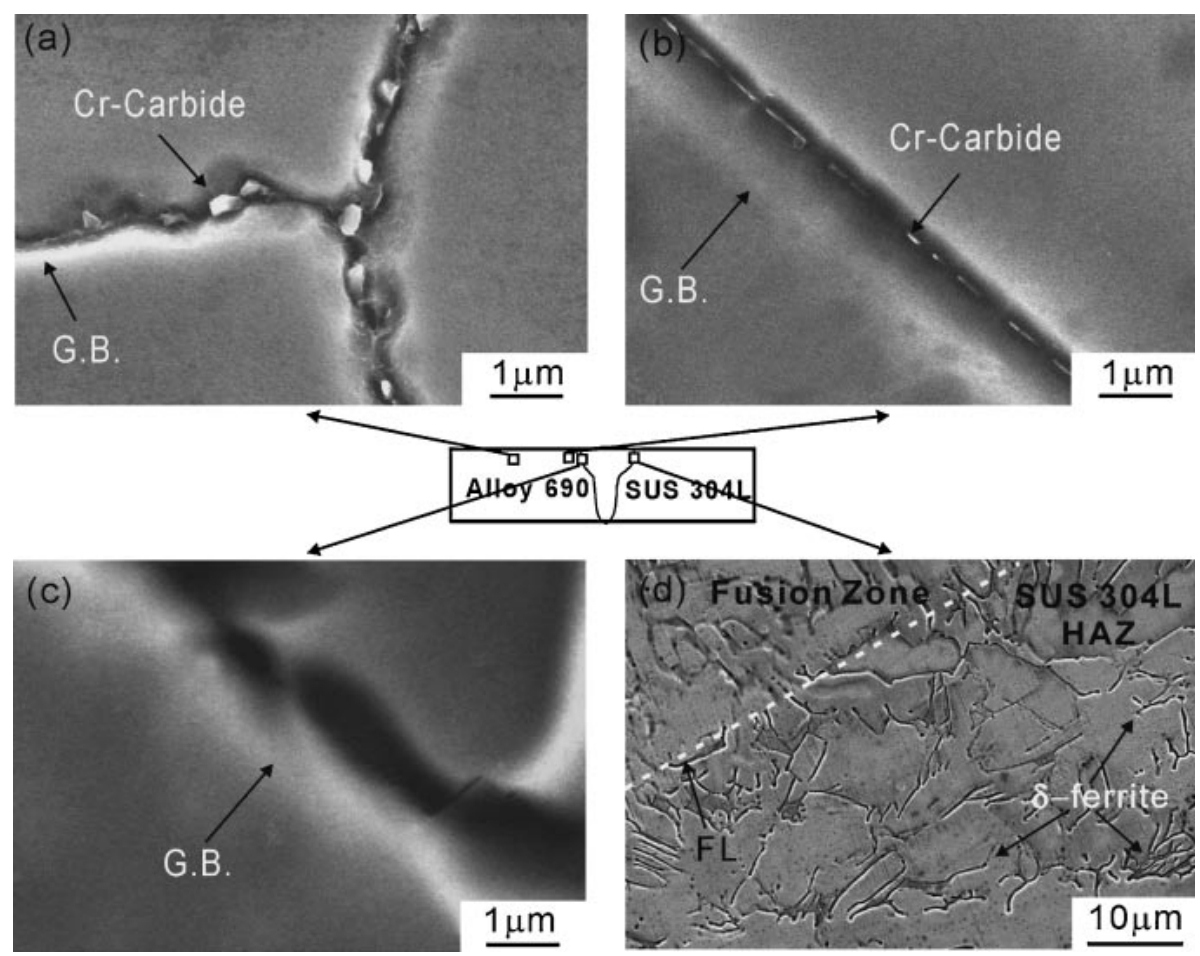

Fig. 4 SEM micrographs of microstructure and precipitates formed in HAZ of the EBW weldment and in Alloy 690 base metal: (a) Alloy 690 base metal, (b) distant from fusion zone in Alloy $690 \mathrm{HAZ,} \mathrm{(c)} \mathrm{near} \mathrm{fusion} \mathrm{zone} \mathrm{in} \mathrm{Alloy} 690$ HAZ, and (d) HAZ in SUS 304L SS. 


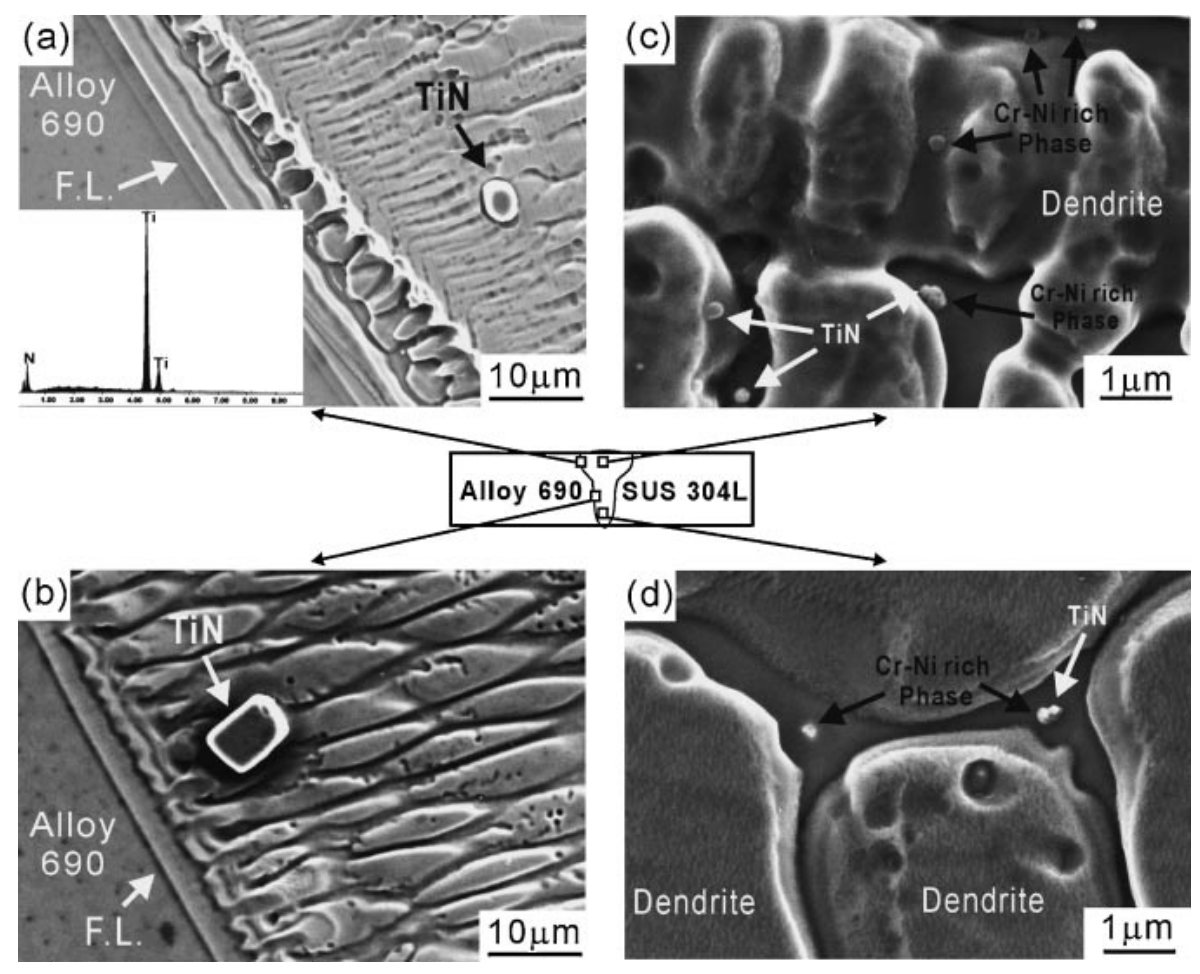

Fig. 5 Microstructure of precipitates in fusion zone of the EBW weldment: (a) near Alloy 690 base metal in cap region (inset shows EDS analysis of TiN), (b) near Alloy 690 base metal in root, (c) in cap, and (d) in root.
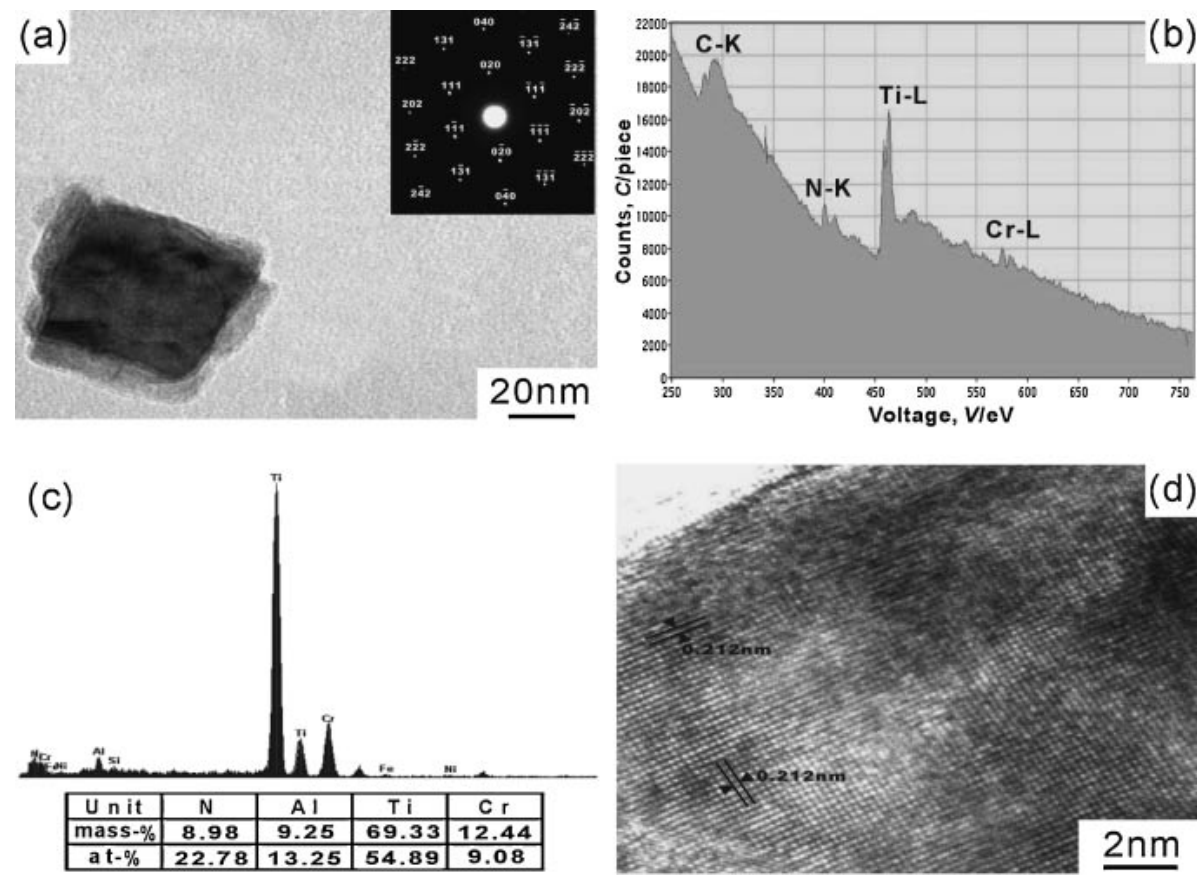

Fig. 6 TEM analysis of TiN (carbon extraction replica): (a) micrograph and SADP in [101] zone axis of TiN, (b) EELS spectrum of TiN, (c) representative EDS spectrum of TiN, and (d) lattice image of TiN precipitate showing (200) d-spacing of $0.212 \mathrm{~nm}$.

that they are TiN either not melted at all during the EBW process, or are only partially melted. Figures $6(\mathrm{a})$ and $6(\mathrm{~d})$ present the TEM SADP analysis results for the TiN precipitates and the corresponding lattice image, respectively. TiN has its lattice parameter by $0.424 \mathrm{~nm}$. Calculation based on lattice image of Fig. 6(d) reveals that the (200) dspacing has the value of $0.212 \mathrm{~nm}$. These findings are consistent with those reported by Berry et al. in. ${ }^{24)}$

Figure 7 shows that the TEM analysis of $\mathrm{Cr}-\mathrm{Ni}$ rich phase. The EDS analysis results presented in Fig. 7(c) reveal that these precipitates consist predominantly of chromium (45.51 masss-\%) and nickel (35.79 masss-\%). The composition of this $\mathrm{Cr}-\mathrm{Ni}$ rich phase is different from that of the $\mathrm{Cr}_{23} \mathrm{C}_{6}$ phase identified in the as-delivered Alloy 690 base 

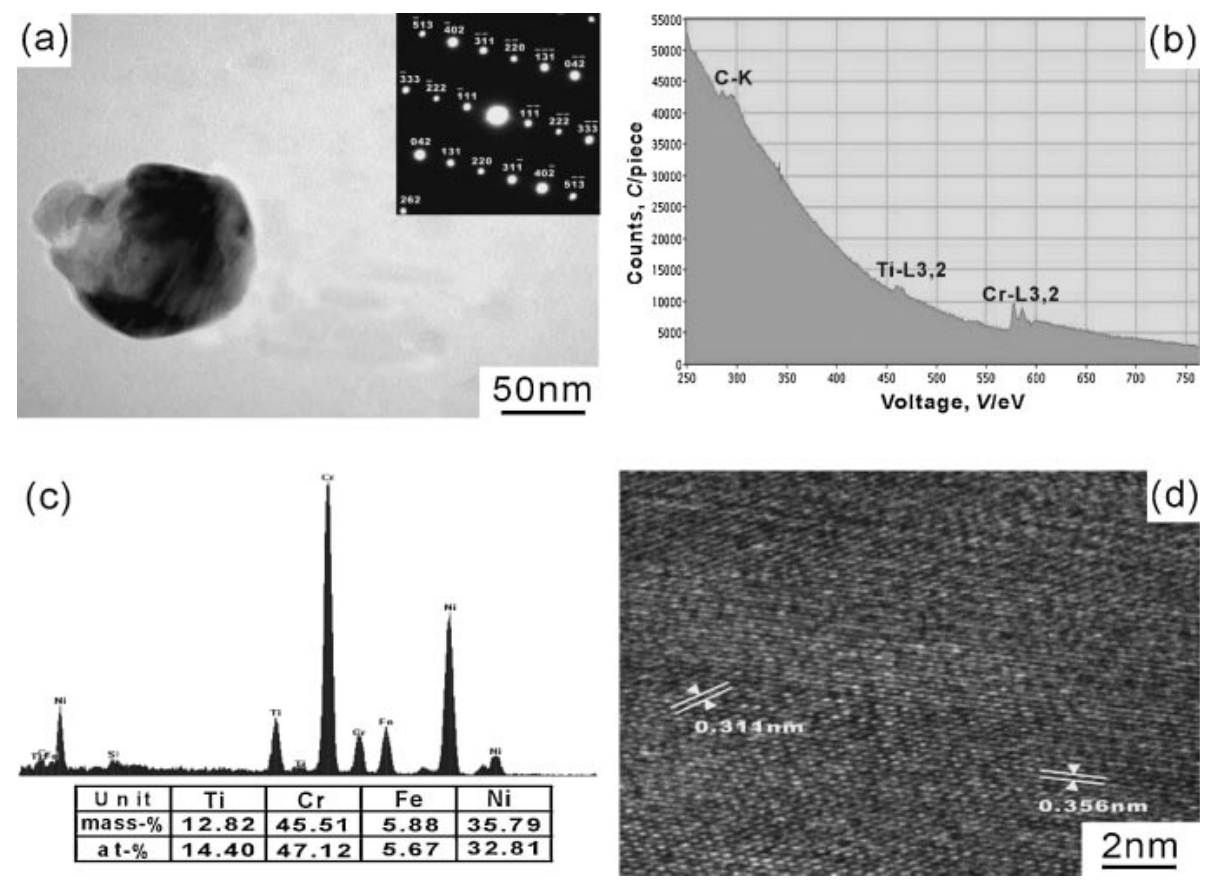

Fig. 7 TEM analysis of $\mathrm{Cr}-\mathrm{Ni}$ rich phase (carbon extraction replica): (a) micrograph and electron diffraction pattern of $\mathrm{Cr}$-Ni rich phase, (b) EELS spectrum of $\mathrm{Cr}-\mathrm{Ni}$ rich phase, (c) representative EDS spectrum of $\mathrm{Cr}-\mathrm{Ni}$ rich phase, and (d) lattice image of $\mathrm{Cr}-\mathrm{Ni}$ rich phase showing (220) and (311) d-spacings of $0.356 \mathrm{~nm}$ and $0.311 \mathrm{~nm}$, respectively.
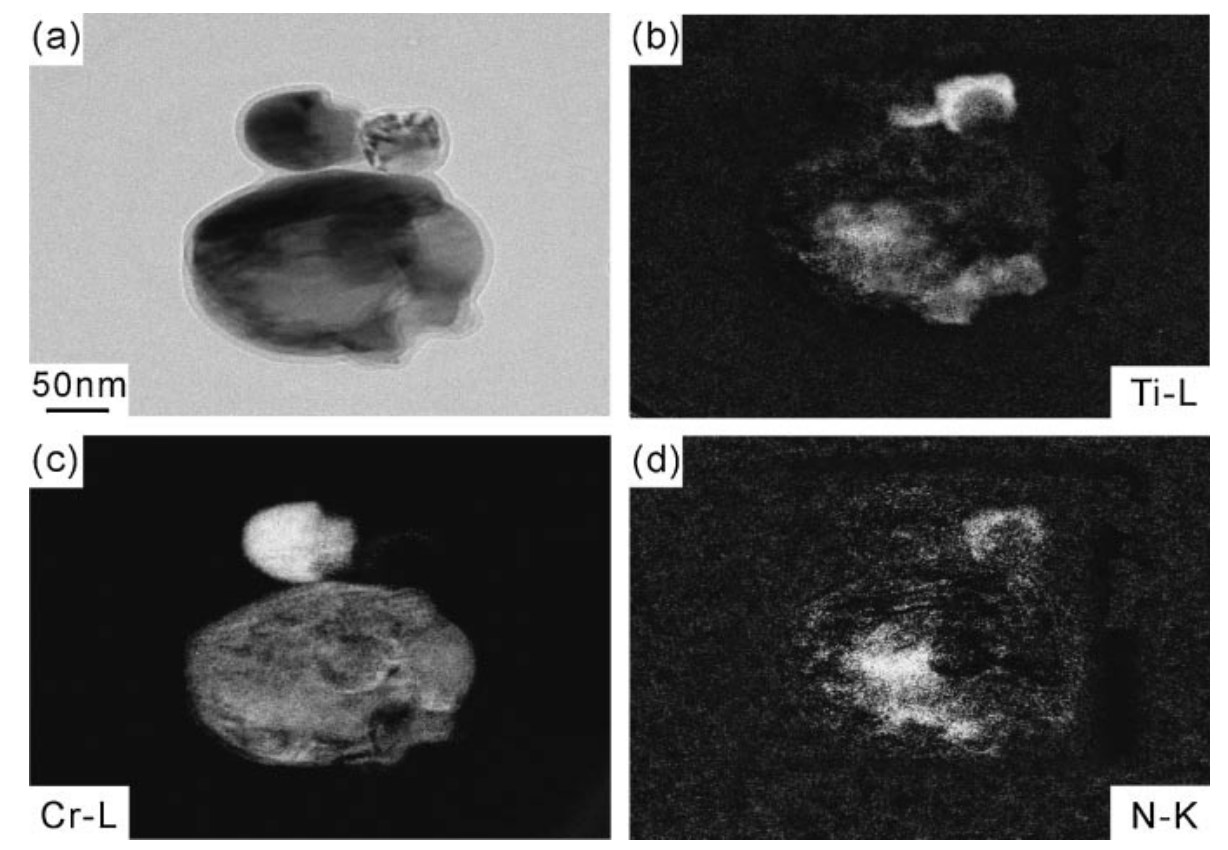

Fig. 8 Bright field image and energy-filtered TEM image of TiN and Cr-Ni rich phase: (a) TEM bright field image, (b) Ti mapping, (c) Cr mapping, and (d) $\mathrm{N}$ mapping.

metal (see Fig. 2). Moreover, the d-spacings of the Cr-Ni rich phase $(0.356 \mathrm{~nm}$ by $(200) \mathrm{d}$-spacing and $0.311 \mathrm{~nm}$ by $(311) \mathrm{d}$ spacing, respectively, as shown in Fig. 7(d)) are also different from those of the $\mathrm{Cr}_{23} \mathrm{C}_{6}$ phase. These oval precipitates are most likely new precipitates formed during solidification process. Since the $\mathrm{Cr}-\mathrm{Ni}$ rich phases are quite small, their formation is unlikely to result any chromium depletion in the fusion zone. Instead, it is far from abundant which on the other side reduces the risk of severe interdendritic corrosion susceptibility.
The TEM mapping results presented in Fig. 8 show the formation of $\mathrm{Cr}-\mathrm{Ni}$ rich phases adjacent to the $\mathrm{TiN}$ precipitates. The co-formation of these two phases is quite popular in fusion zone. Since the melting point of TiN is higher than that of the $\mathrm{Cr}-\mathrm{Ni}$ rich phases, the TiN precipitates are formed first at high temperature during the cooling process. These TiN precipitates then provide nuclei for the subsequent formation of the neighboring $\mathrm{Cr}-\mathrm{Ni}$ rich precipitates. 


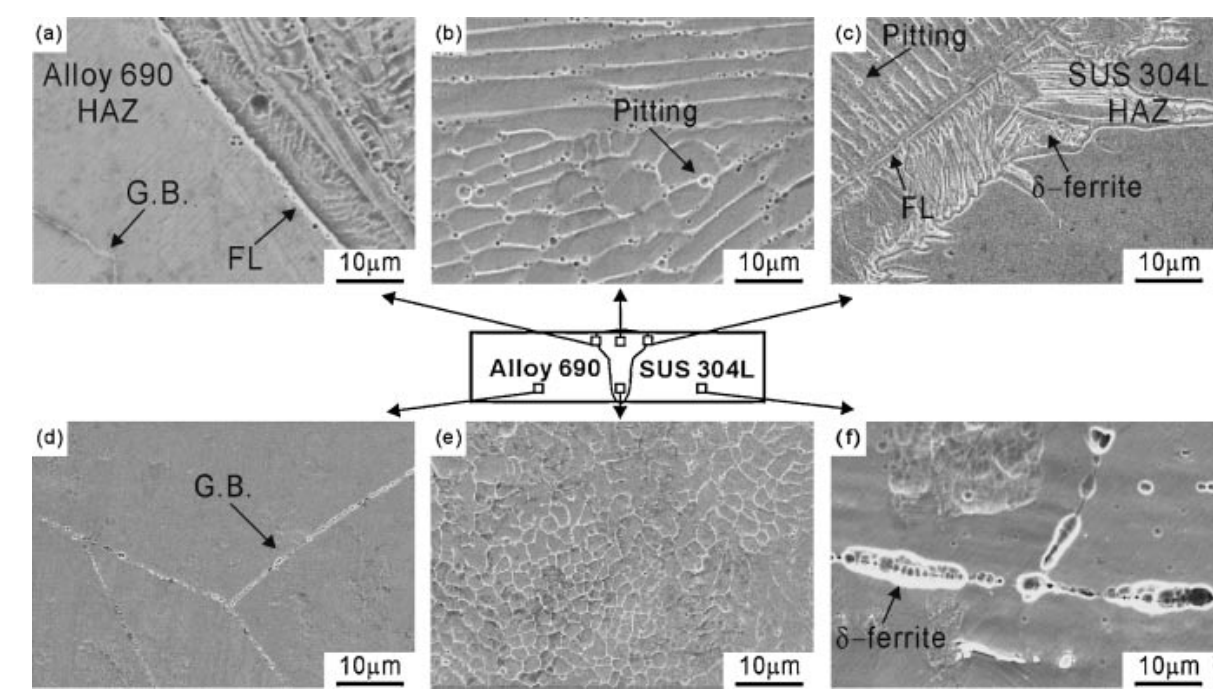

Fig. 9 Corroded surface of the EBW weldment after modified Huey test: (a) cap welded face near Alloy 690, (b) cap welded face near centerline, (c) cap welded face near SUS 304L SS base metal, (d) Alloy 690 base metal, (e) root welded face near centerline, and (f) SUS 304L SS base metal.

\subsection{Corrosion resistance}

\subsubsection{Correlation between composition of fusion zone, precipitates and corrosion resistance}

The SEM micrographs presented in Fig. 9 show the surface morphology of the EBW weldment after the modified Huey test. Corrosion resistance of the fusion zone varies from ort to ort, depends on the influence of the compositional dilution from the base metal. Region near Alloy 690 side has better corrosion resistance, followed by center region of the fusion zone. Region near 304L SS side has the worst corrosion resistance, as shown in Figs. 9(a), 9(b) and 9(c). This trend is in good accordance with the varied chromium content of the weldment and confirms a previous report that a higher chromium content favors the ability to resist corrosion. ${ }^{10)}$ Figures 9 (b) and $9(\mathrm{e})$ show that the pitting corrosion in the cap region of the fusion zone is more severe than that in the root. It is correlated to the cooling rate. Root region in fusion zone has a faster cooling rate than cap region which results less precipitates to form. Consequently, the root has a better corrosion resistance than the cap. Similarly, since the HAZ near Alloy 690 base metal side has fewer chromium carbides at the grain boundary (Fig. 4(b)), the pits formed in this region are both smaller in size and fewer in number than those formed in the Alloy 690 base metal itself, micrograph in Figs. 9(a) and 9(d) are the evidence. By contrast, HAZ of 304L SS side and 304L SS reveal a much more severe corrosion since there is a large number of $\delta$-ferrite particles formed which speeds the corrosion (Fig. 9(c) and 9(f)).

Figure 10 presents the SEM images of the surfaces of the various precipitates according to their on site location of the EBW weldment after the modified Huey test. As indicated by the white arrows in Figs. 10(a) and 10(b), corrosion occurs primarily in the matrix around the TiN precipitates and the $\mathrm{Cr}-\mathrm{Ni}$ rich phase, respectively. Pitting corrosion also takes place in the matrix around the chromium carbide at the grain boundary in the Alloy 690 HAZ (Fig. 10(c)) and in the matrix around the $\delta$-ferrite particles in the SUS 304L SS HAZ (Fig. 10(d)). The pitting corrosion observed in the weldment is the result of the compositional difference between the precipitates and the matrix. This compositional difference leads to a disparity in the electrochemical potentials of the precipitates and the matrix, respectively, which in turn prompts galvanic corrosion. ${ }^{25,26)}$ Once the periphery of the precipitate has been fully corroded, it drops out of the matrix, resulting in the formation of a surface pit. ${ }^{27)}$ Clearly, therefore, the interdendritic corrosion resistance of the fusion zone is fundamentally dependent on the size and volume fraction of the precipitates.

The number of TiN and $\mathrm{Cr}-\mathrm{Ni}$ rich phase precipitates in the interdendritic region of the current Alloy 690-SUS 304L SS dissimilar weldments is quite low. Moreover, the average size of these precipitates is very small (i.e. in the $\mathrm{nm}$ range). Therefore, the corrosion pits are relatively few in number and small in size. As a result, the fusion zone has favorable interdendritic corrosion resistance properties. However, due to the rapid cooling rate in the EBW process, the $\delta$-ferrite in the SUS 304L SS HAZ has insufficient time to dissolve in the matrix. Furthermore, the proportion of the various alloy elements in the $\delta$-ferrite differs from that in the matrix and hence a disparity exists in the electrochemical potentials of the $\delta$-ferrite and the matrix, respectively. This disparity prompts preferential corrosion at the matrix around the $\delta$ ferrite in SUS 304L HAZ, as shown in Fig. 10(d).

\subsubsection{Comparison of corrosion resistance of fusion zone in EBW and GTAW weldments}

Comparing the welding parameters in Tables 2 and 4, it is observed that the total heat input during the GTAW process $\left(7.83 \mathrm{~kJ} \cdot \mathrm{mm}^{-1}\right)$ is much higher than that input during the EBW process $\left(0.026 \mathrm{~kJ} \cdot \mathrm{mm}^{-1}\right)$. Figure 11 (a) shows the presence of rectangular chromium rich carbide precipitates at the grain boundary in the fusion zone of the GTAW weldment. The TEM diffraction pattern is well indexed as that the precipitates are $\mathrm{Cr}_{7} \mathrm{C}_{3}$. The presence of these precipitates is the consequence of the high number of welding passes in the GTAW process (i.e. a high total heat input) and the slow cooling rate. The formation of these chromium rich carbide precipitates causes a chromiumdepletion zone near the grain boundary and therefore reduces 


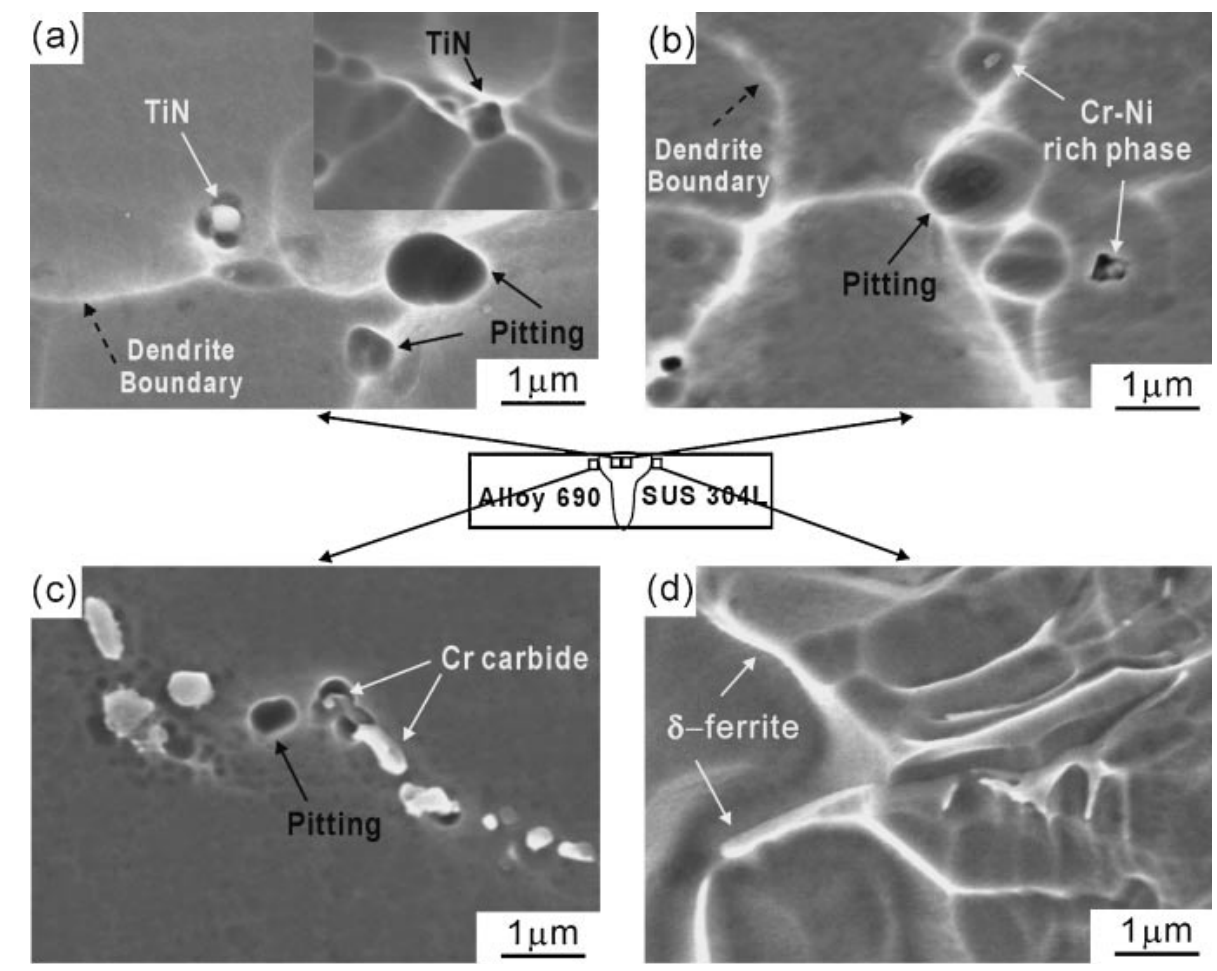

Fig. 10 SEM micrographs of precipitates according to their on site location of the EBW weldment after modified Huey test: (a) TiN precipitates in fusion zone, (b) Cr-Ni rich phase in fusion zone, (c) chromium carbide in Alloy $690 \mathrm{HAZ}$, and (d) $\delta$-ferrite in SUS 304L SS HAZ.
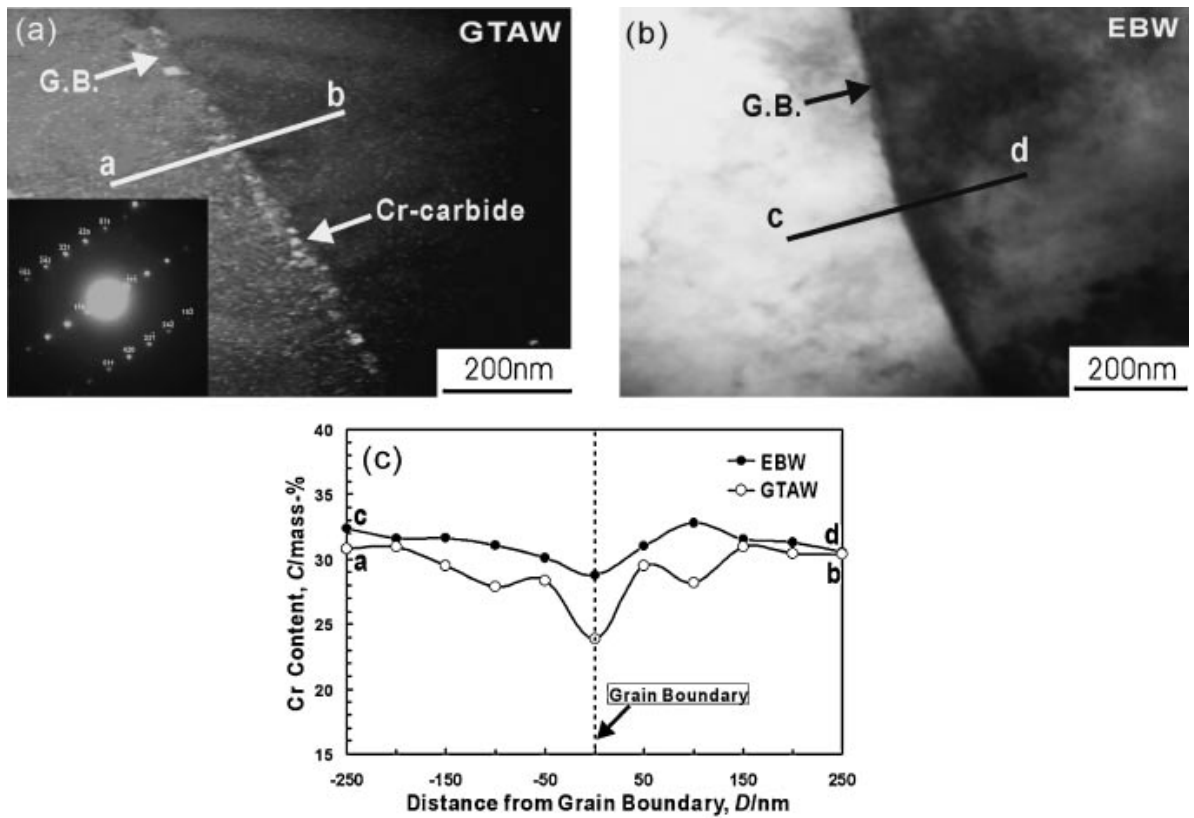

Fig. 11 TEM bright-field images of microstructure around grain boundary in: (a) GTAW fusion zone (inset shows electron diffraction pattern of chromium carbide) and (b) EBW fusion zone; (c) variation of chromium content across grain boundary in fusion zones of GTAW and EBW weldments.

the intergranular corrosion resistance of the GTAW fusion zone. By contrast, the high cooling rate of the EBW process suppresses the precipitation of chromium carbide at the grain boundary, as shown in Fig. 11(b). Hence, Fig. 11(c) shows that the chromium content at the grain boundary varies between 28.79 mass- $\%$ and 32.82 mass- $\%$ of the EBW fusion zone. The chromium-depletion zones are not formed near the grain boundary in the fusion zone of the EBW weldment. Therefore, as shown in Fig. 11(c), the minimum chromium concentration at the grain boundary in the fusion zone of the EBW weldment (28.79 mass-\%) is higher than that in the GTAW weldment (23.87 mass- $\%$ ) and consequently the EBW weldment has an improved intergranular corrosion resistance. 

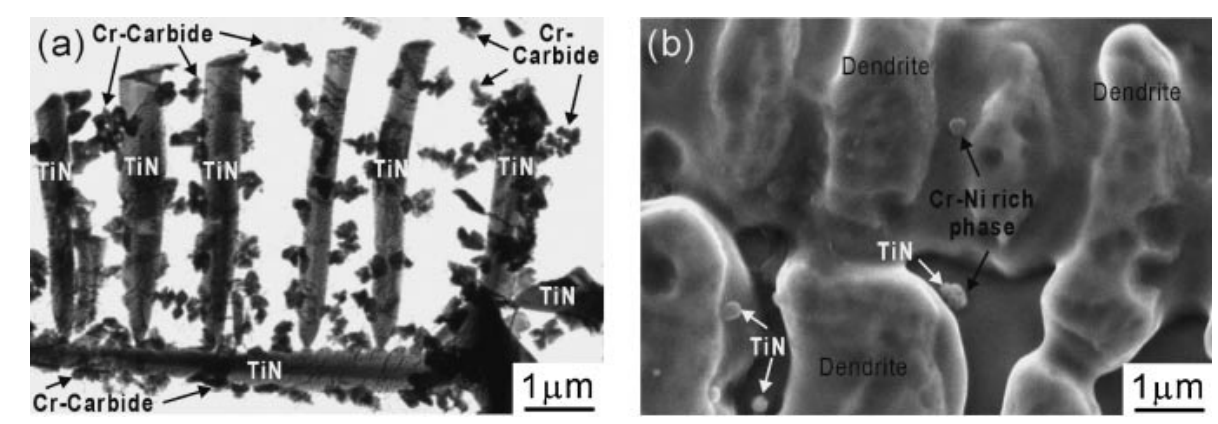

Fig. 12 SEM micrographs of interdendritic precipitates in: (a) GTAW weldment and (b) EBW weldment.

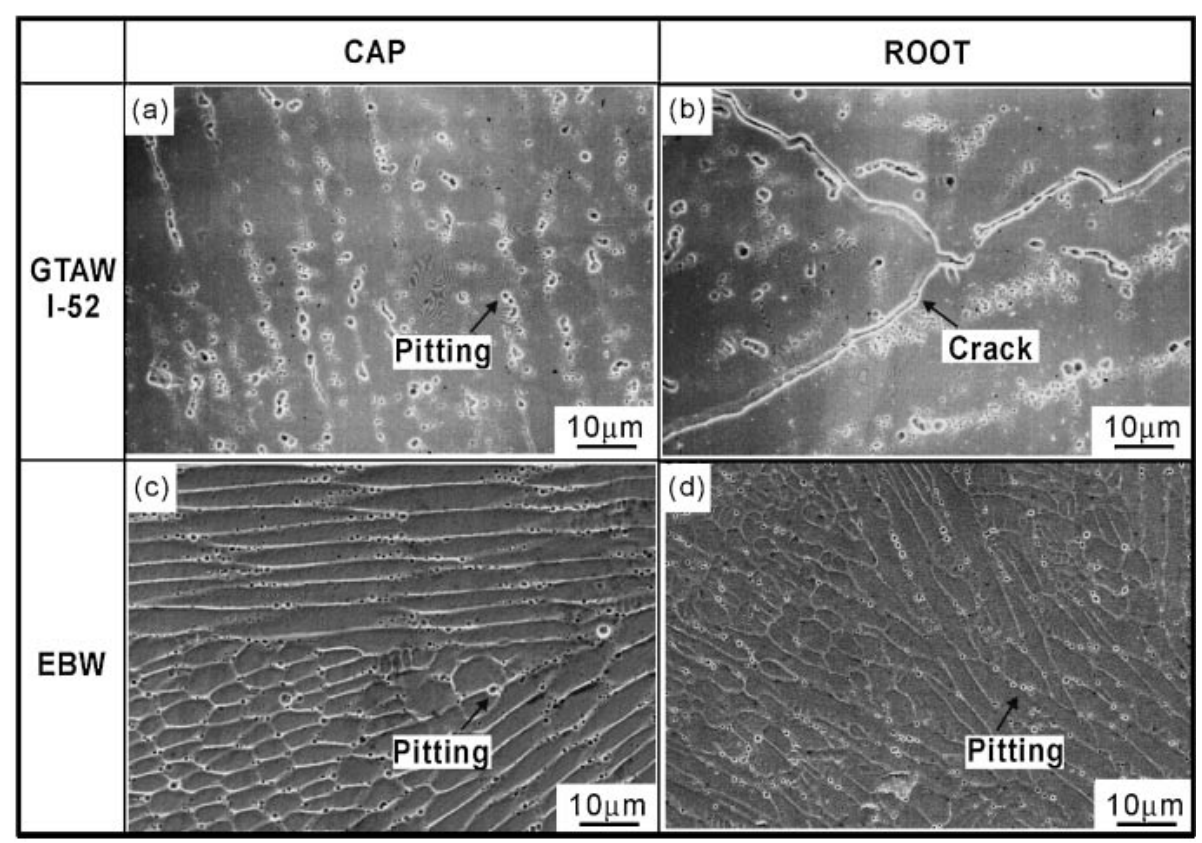

Fig. 13 Micrographs of corroded surface after modified Huey test: (a) cap of GTAW weldment, (b) root of GTAW weldment, (c) cap of EBW weldment, and (d) root of EBW weldment.

Figure 12(a) and 12(b) present SEM micrographs of the interdendritic precipitates in the fusion zones of the GTAW and EBW weldments, respectively. Figure 12(a) shows that the GTAW weldment contains a mixture of chromium carbide precipitates with an irregular shape and TiN phases with a rectangular shape. Comparing Figs. 12(a) and 12(b), it is seen that the precipitates in the GTAW weldment are greater in number than that in the EBW weldment and the TiN precipitates in the GTAW weldment are larger in size than that in the EBW weldment. Again, this is a consequence of the higher heat input during the GTAW welding process and the slower cooling rate.

Figure 13 presents micrographs of the cap and root regions of the GTAW and EBW weldments after the modified Huey test. Of the two weldments, it can be seen that the GTAW fusion zone has more severe pitting corrosion and shows clear signs of corrosion cracking. In other words, the intergranular corrosion and interdendritic corrosion resistance of the EBW fusion zone is superior to that of the GTAW fusion zone. This observation is consistent with the findings presented above regarding the microstructures of the two weldments, namely that the precipitates formed in the EBW weldments are both fewer in number and smaller in size than those in the GTAW weldments, and the chromium concentration at the grain boundary in the fusion zone of the EBW weldment is greater than that in the fusion zone of the GTAW weldment.

\section{Conclusions}

(1) The interdendritic region in the fusion zone of the EBW weldment contains predominantly TiN precipitates and $\mathrm{Cr}-\mathrm{Ni}$ rich phases. The TiN precipitates originate from the Alloy 690 base metal, while the $\mathrm{Cr}-\mathrm{Ni}$ rich phases are a new precipitate formation precipitated in the region surrounding the TiN phase during the solidification process.

(2) The results of the modified Huey test reveal that the matrix around TiN precipitate and the $\mathrm{Cr}-\mathrm{Ni}$ rich phase precipitate in the interdendritic region of the fusion zone of the EBW weldments act as preferential sites for corrosion pit initiation. Besides, as the cooling speed of EBW is faster than that of GTAW, the precipitates in the EBW weldment are fewer in number than that in the 
GTAW weldment and the TiN precipitates in the EBW weldment are smaller in size than that in the GTAW weldment.

(3) During the EBW process, the rapid solidification in the fusion zone suppresses the formation of chromium-rich carbides at the grain boundary. The EDS analysis results reveal that the chromium content at the grain boundary varies from 28.79 mass- $\%$ and 32.82 mass- $\%$. These results indicated that a chromium depletion zone is not formed at the grain boundary and hence the effects of intergranular corrosion are suppressed.

(4) The interdendritic precipitates formed in the fusion zone of the GTAW weldment are greater in number than those formed in the fusion zone of the EBW weldments. Furthermore, the chromium content at the grain boundary in the fusion zone of the GTAW weldments is lower than that in the fusion zone of the EBW weldments. Consequently, the GTAW weldments have a significantly lower intergranular corrosion and interdendritic corrosion resistance than their EBW counterparts.

\section{Acknowledgements}

The current authors gratefully acknowledge the financial support provided to this study by the National Science Council of Taiwan under grant number NSC 91-2626-E-232002.

\section{REFERENCES}

1) T. Ishihiara: Weld. J. 68 (1989) 209-216.

2) B. E. Payne: Met. Constr. 1 (1969) 79-86.

3) J. D. Kim and J. H. Moon: Corros. Sci. 46 (2004) 807-815.
4) G. Sui, J. M. Titchmarsh, G. B. Heys and J. Congleton: Corros. Sci. 39 (1997) 565-573.

5) J. R. Crum and R. C. Scarberry: J. Mater. Energy Syst. 4 (1982) 125130.

6) H. Coriou, L. Grall, C. Mahine and M. Pelas: Corrosion 22 (1966) 280290.

7) W. T. Wu and C. H. Tsai: Metall. Trans. A 30A (1999) 417-426.

8) K. Stiller, J. O. Nilsson and K. Norring: Metall. Mater. Trans. A 27A (1996) 327-341.

9) T. Y. Kuo and H. T. Lee: Mater. Sci. Eng. A 338 (2002) 202-212.

10) H. T. Lee and S. L. Jeng: Sci. Technol. Weld. Joi. 6 (2001) 225-234.

11) H. T. Lee and T. Y. Kuo: Sci. Technol. Weld. Joi. 4 (1999) 94-103.

12) S. L. Jeng, H. T. Lee, W. P. Rehbach, T. Y. Kuo, T. E. Weirich and J. P. Mayer: Mater. Sci. Eng. A 397 (2005) 229-238.

13) H. T. Lee, S. L. Jeng, C. H. Yen and T. Y. Kuo: J. Nuc. Mater. 335 (2004) 59-69.

14) H. T. Lee, S. L. Jeng and T. Y. Kuo: Metall. Trans. A 34 (2003) 10972005.

15) T. Y. Kuo, H. T. Lee and C. C. Tu: Sci. Technol. Weld. Joi. 8 (2003) 39-48.

16) Z. Sun and R. Karppi: J. Mater. Process. Technol. 59 (1996) 257-264.

17) Y. S. Lim, J. S. Kim and H. S. Kwon: Mater. Sci. Eng. A 279 (2000) 192-200.

18) Y. S. Kim, J. H. Suh, I. H. Kuk and J. S. Kim: Metall. Trans. A 28A (1997) 1223-1231.

19) A. Czyrska-Filemonowicz and K. Spiradek: Eur. Microscopy Anal. 3 (1995) 13-14.

20) J. J. Kai, G. P. Yu, C. H. Tsai, M. N. Liu and S. C. Yao: Metall. Trans. A 20A (1989) 2057-2067.

21) T. M. Angeliu and G. S. Was: Metall. Trans. A 21A (1990) 2097-2107.

22) R. S. Dutta and R. Tewari: Bri. Corros. J. 34 (1999) 201-205.

23) S. A. David: Weld. J. 60 (1981) 63-71.

24) L. G. Berry, B. Post and S. Weissman: Power Diffraction File, 2nd ed., Joint Committee on Power Diffraction Standards, (Swarthmore, PA, 1980) Sets 6-10.

25) W. T. Tsai, C. L. Yu and J. I. Lee: Scripta Materialia 53 (2005) 505509.

26) L. Reclaru, R. Lerf, P. Y. Eschler and J. M. Meyer: Biomaterials 22 (2001) 269-274.

27) I. H. Lo and W. T. Tsai: Mater. Sci. Eng. A 355 (2003) 137-143. 